\title{
Trayectoria de Fernández Moreno
}

En las Explicaciones que preceden su Antologia (1915-1940) estampó Fernández Moreno un párrafo que con posterioridad se ha repetido a menudo. Decía allí el poeta:

Ahora veo que la poesía ha seguido con fidelidad mis pasos sobre el mundo: el pedazo de patria que me tocó vivir, ciudad, pueblo o campo, el amor, el hogar, los hijos, la sangre, mis trabajos y mis vacaciones. Todo está más o menos representado en mi acervo. Hay una impresionante unidad que, por cierto, no me propuse jamás, pues sólo atendí a la exhalación natural de mi ser...

Reparemos, sobre todo, en la "impresionante unidad" que el autor destaca. Por otra parte, Fernández Moreno coincide aquí con juicios de la mayoria de sus críticos, anteriores a 1941. Y con buena parte de los que vinieron después (se apoyen en sus palabras o no).

Sin embargo, debemos ver una nueva perspectiva en el libro fundamental que sobre Fernández Moreno escribió su hijo César, libro que desde el momento de su aparición se convirtió en punto de referencia obligado para todos aquellos que se interesen por la obra de nuestro autor.

¿Qué nos dice César Fernández Moreno? Concretamente, que la crítica ha visto en la obra de su padre los elementos con permanencia invariable, $\mathrm{y}$ ha descuidado los que evolucionaban. Propone, así, una división cronológica en tres épocas a las que da los nombres de sencillista, formal y sustancial. Epocas como unidades dialécticas, y en consonancia con su vida. ${ }^{2}$

1 Cf. Fernández Moreno, Antologia (1915-1940), Buenos Aires, 1941, pp. $20-21$.

2 Cf. César Fernández Moreno, Introducción a Fernández Moreno, Buenos Aires, 1956. Y también la síntesis posterior, incluida en Las cien mejores poesias de Fernández Moreno, Buenos Aires, 1961. 
La época sencillista - dice- se extiende desde 1910 hasta 1923. La considera antimodernista o - -según dice en otro lugar- escala intermedia entre el modernismo y el vanguardismo. Se caracteriza -agrega- por composiciones de temas objetivos, sacados de la realidad, y su versión impresionista o expresionista. También, por la espontaneidad sentimental. Se refleja en poemas breves, sin mayor cuidado por la forma poética. Algunos ejemplos: "Habla la madre castellana", "Barrio característico", "Crepúsculo" ("El cielo azul...").

La segunda etapa, a la que llama formal, la extiende desde 1923 hasta 1937. Corresponde a los años de radicación definitiva del poeta en Buenos Aires. Este período se caracteriza por su mayor preocupación "literaria", con aprovechamiento de temas de la experiencia urbana y de la cultura superior; de formas clásicas modernizadas. Con entiquecimiento de la lengua y cierto barroquismo. Algunos ejemplos: "Epístola de un verano", "A una mujer que me evocaba el mar", "Décimas a la vida".

La tercera y última etapa, que llama sustancial, la extiende entre 1937 y la muerte del poeta en 1950. Es época - señala - en que se dan con mayor fuerza los rasgos precendentes: "la máxima austeridad lírica unida al máximo cuidado formal". Varias pérdidas familiares, depresiones, crisis internas, se reflejan en poemas desgarrados, dolorosamente crepusculares. Aunque hay alternancias explicables. Algunos ejemplos "A una amiga desaparecida hace tiempo", "Soneto" ("No hay nada comparable a este momento..."), "Canción de luna".

Por supuesto, la partición establecida por César Fernández Moreno responde al defendible intento de superar concepciones muy rígidas o muy lineales, a través de las cuales se ve la poesía de Fernández Moreno como un cuerpo que nace ya totalmente formado y que posteriormente poco o nada incorpora a su condición inicial. También César Fernández Moreno, (aunque nos advierte acerca de la originalidad que revela ya ese primer momento) descubre la clara intención de mostrar que no sólo hay cambios, sino - lo que subraya- enriquecimientos y variantes. En fin, ya hemos visto las etapas propuestas.

La tarea emprendida por el hijo del poeta es realmente ardua, por las dificultades que comporta. Y -agrego- porque la lírica de Fernández Moreno no muestra, con tanta claridad como el crítico pretende, esas etapas y las características identificadoras. Pero antes de seguir adelante me complace destacar la inquietud revitalizadora, las necesidades de replanteo que su libro trajo especialmente en este sector.

Hecha esța salvedad, quiero discutir, en primẹ término, los poco 
felices nombres propuestos para enunciar las etapas. Es cierto que el nombre sencillismo se encuentra ya en germen en varias de las reseñas y comentarios que siguen a la aparición de Las iniciales del misal. Y, sobre todo, en el conocido artículo de Leopoldo Lugones publicado en el diario La Nación de Buenos Aires, 1916, con motivo de Intermedio provinciano. Allí, habla Lugones, por un lado, de poesías "claras y sencillas", y, por otro, de un "espíritu de piedad, de sencillez y de dulzura". ${ }^{3}$

Es cierto también que el propio Fernández Moreno, en una entrevista de 1921, define su poesía, en oposición, como "sintética y senci$11 a^{\prime} .4$, en fin, que en el tantas veces recordado soneto "Contra casi todos mis críticos", de 1949, repite lo de "sencillo".5 (Recordemos, de paso, que dicho soneto es, en mucho, una evocación de Lugones y su reiterado juicio, que Fernández Moreno blande contra otros).

En sintesis, a pesar de los testimonios precedentes ( $y$, sobre todo, enfocados con sentido positivo) me parece que el nombre sencillismo es infiel y poco feliz, aun abarcando el período que su hijo pretende.

Con mayor razón quizás, creo poco acertado el nombre de "época formal". Especialmente por las connotaciones que el vocablo formal tiene en la crítica; $Y$, nada digamos, en la critica del siglo $\mathrm{xx} !^{6} \mathrm{Y}$ con esto también ponemos en duda el nombre (y contenido) de sustancial. Claro que, como procuraré mostrar, no se trata sólo de nombres.

Quiero puntualizar aquí que otro enfoque muy discutible lo veo en

3 Ver Leopoldo Lugones, "Otro poeta", (en el diario La Nación, de Buenos Aires, 28 de Diciembre de 1916).

4 Recordado por César Fernández Moreno, Introducción a Fernández Moreno, ed. citada, p. 153 .

A manera de acotación, no está demás decir que hacia 1920 se difundieron las palabras de Juan Ramón Jiménez en las conocidas "Notas" a su Segunda antolojía poética. Juan Ramón Jinénez daba allí esta definición de lo Sencillo: "Lo conseguido con los menos elementos; es decir, lo neto, lo apuntado, lo sintético, lo justo. Por lo tanto, una poesía puede ser sencilla y complicada a un tiempo, según lo que pretende explicar". Ver J. R. J., Segunda antolojía poética (1898-1918), Madrid-Barcelona, 1920, p. 320).

Fácilmente se advierte que no es esta caracterización la que más conviene a la poesía de Fernández Moreno. Aunque también puede cuestionarse que sea una convincente definición. Por lo tanto -y sin pretender más que una relación de época- no resulta apropiada para aplicar a la obra del poeta argentino.

5 Ver Fernández Moreno, Parva, Buenos Aires, 1949, p. 67.

6 Podemos recordar, también, que Jorge Guillén, defendiendo a los hombres de su generación de la tacha de "formalismo", atacaba el nombre y argüía: "Claro que el semi ignorante de hoy llama - con porte de fiscal- formalismo a la plenitud de una forma bien trabajada, es decir, cuidadosamente ajustada a su contenido". (J. Guillén, Lengmaje y poesía, ed. de Madrid, 1969, p. 186).

Notemos, al pasar, que hay cierta coincidencia cronológica entre el Fernández Moreno "fomalista" (de la periodización de César) y los poetas españoles que defiende Guillén. $Y$ entre los cuales, claro, él se incluye. 
el intento de César Fernández Moreno de aproximar forzadamente la poesía de su padre, en el lapso 1920-1925, con la poesía de los van. guardistas. Comencemos por el hecho de que en Fernández Moreno no hay una reacción total contra el modernismo, y sí más de una continuidad. El sentimentalismo, la anécdota, el respeto por formas tradicionales y por ciertas novedades modernistas... En fin, los vanguardistas no lo vieron como uno de los suyos, ni siquiera como precedente inmediato (aunque lo respetaron, en general, como hombre) ${ }^{7}$ Pero, claro está, no cabe duda de que el elemento fundamental es el que da la poesía en sí.

Evar Méndez reunia a Fernández Moreno con Banch y Capdevila, como influencia no deseable para el vanguardismo. $Y$ Borges hablaba, en 1925, de "los taciturnos de la parvilocuencia rimada -fernandezmodernistas y otros canturreadores del verso..."). Lo cual no impide reconocer que, también en 1925, Borges elogiaba poesías de Aldea española, y que un año antes, Pablo Rojas Paz había elogiado, en la revista Martin Fierro, El bogar en el campo. ${ }^{8}$

Alguna leve aproximación entre Fernández Moreno y los vanguardistas no alcanza para acercar las dos poesías. He aquí un entero poema de Fernảndez Moreno:

Ocre y abierto en huellas, el camino separa opacamente los sembrados... Lejos, la margarita de un molino.

("Paisaje", en Intermedio provinciano, 1916)

Pero, claro está que no era, en lo esencial, la poesía de Fernández Moreno lo que pretendían los vanguardistas. $O$, mejor, lo que pretendían los vanguardistas argentinos. En Fernández Moreno la metáfora es un elemento entre varios. No, el esencial. No, "el poema". (Repito: algunas semejanzas no invalidan lo que digo). En Fernández Moreno el verso libre no es cauce de poesía. En Fernández Moreno (el que corresponde a los años 1920-1925) no encontramos abstracciones, ni oscuridades, ni espectacularidades detonantes (de expresión, tipográficas, etc.).

Con todo, me parece justo recordar que es el propio César Fernández Moreno el que, en páginas finales de su libro, expresa minuciosamente

\footnotetext{
"Cf. con mi estudio sobre "El vanguardismo en la Argentina" (en Estudios de literatura argentina (Siglo XX), ed. de Buenos Aires, 1968, p. 65,

- Id. p. 65-66.
} 
las dificultades que se oponen a una periodización estética de la obra de su padre. Para concluir que "Fernández Moreno es el típico poeta de la generación intermedia que separa al modernismo del vanguardis. mo". ${ }^{9}$ Naturalmente, este reconocimiento final no borra su clasificación, peto creo que nos retrotrae a una realidad posiblemente más defendible (y más aceptada, en general).

Después de lo expuesto, quiero reiterar que, si bien el enfoque de César Fernández Moreno no me convence, lo veo como un acicate fecundo por la obligación de replanteos que nos exige. Por la incitación a nuevas búsquedas y agrupamientos. $\mathrm{Y}$ esto, fundamentalmente, es lo que tenemos que agradecerle a César Fernández Moreno.

Por lo pronto, quiero anticipar que mi intento será menos llamativo que el suyo. $Y$ defiendo una vez más esta posición porque si ahora creo que pueden verse momentos o etapas en la poesia de Fernández Moreno, no abandono una cautela que - creo- su propia obra respalda. $O$, si preferimos, a que su propia obra obliga.

En concreto, señalo en la obra de Fernández Moreno dos momentos. Dos momentos con interpenetraciones profundas, a los cuales no convie. ne dar nombres precisos. O para los cuales no encuentro nombres pre. cisos, salvo el que marcan los dos ordinales.

En los aproximadamente cuarenta años que abarca la trayectoria lírica de Fernández Moreno creo distinguir dos extendidos momentos o etapas, cuya línea divisoria podria marcarse hacia 1928. Aunque sin dar a este año (por las causas aducidas) un valor decisivo: sólo la necesidad de fijar un límite más o menos convincente.

Defiendo, asi, un primer momento, que extiendo desde la iniciación hasta la madurez del poeta. El segundo, de sedimentación, enriquecimiento y variantes. Remedando el título de uno de sus libros, podríamos establecer, en forma un tanto pintoresca, el período de "Yo, médico... y poeta" (o "Yo poeta... y médico"), y el período de "Yo, catedrático... y poeta" (o, "Yo poeta. .-. y catedrático"). Pero ya vemos que esto sirve de paco

Más importancia - subrayo- tiene la fundamentación de los dos momentos y el porqué de ese no muy preciso año 1928 como punto divisorio.

- Ver César Fernández Moreno, Introducción a Fernández Moreno, ed. citadạ, p. 248. Cerca, alguna coincidencia çon un juiçio de Françisço Luis Bernárdez. 


\section{Primer Momento}

El primer momento se proyecta, en principio, hacia afuera (paisaje "vivido") y hacia atrás (infancia recuperada). Descripciones, impresiones y evocaciones.

Más adelante, se proyecta hacia adentro: amor; pero, también, humor, melancolía, y ráfagas tétricas (muerte). Algún toque "social" muy breve.

Nuevos avances con el hogar, el hijo: optimismo. Y, por supuesto, entrecruzamientos de temas: paisaje, evocación, amor, etc.

Mundo transparente (a veces, ingenuo) despintado de complejidades. Como auténtico postmodernista, recoge Fernández Moreno algunas líneas de la corriente finisecular. Más que en los temas, en la métrica, en procedimientos como la técnica impresionista, y en formas definidas de la lengua poética.

Dentro de la lírica de Fernández Moreno destaquemos la alternancia de imágenes y metáforas; el adjetivo cromático; las series de enumeraciones, repeticiones y paralelismos.

En fin, la abundancia de temas comunes, y la presencia de prosaísmos expresivos. Como proximidad que aún tiene vigencia, el médico llega a la lengua poética en algunos poemas. Vocablos que posteriormente desaparecerán por completo.

Es indudable que el estímulo de la realidad y su representación en la obra no se da en forma igual en todos los autores. En fin, que hay grados o niveles que es necesario señalar. Asi, para mostrarlo con ejemplos rotundos, el nivel de un poeta como Fernández Moreno (sobre todo, el Fernández Moreno de esta etapa) y aun el de un poeta como Antonio Machado (sobre todo, el Antonio Machado de los primeros libros) está más cerca de la realidad aludida que, valga el ejemplo, el caso que of rece un poeta como Jorge Guillén. La comparación no me parece forzada, ya que es bien sabido que Jorge Guillén parte común. mente en sus poemas (en especial, en los de su Cántico) de la realidad más inmediata, de cosas o hechos notorios.

En la métrica, la verdadera situación "postmodernista" de Fernández Moreno se ve, más que en la variedad manifiesta, en el uso de formas nada complicadas, aunque es indudable que esas formas debían su difusión a los modernistas. Por ejemplo: el soneto alejandrino, el alejandrino con rima de romance, los alejandrinos pareados, la silva arrot manzada, el endecasílabo blanco. Agreguemos, de manera menos pre- 
cisa: el soneto endecasílabo, el romance, el romancillo, la décima (por (as) ${ }^{10}$

\section{Segundo Momento}

Este segundo momento se respalda en varios temas. Temas que - -sabemos- no pueden desligarse de su vida (con el "médico" desapare. cido, pero con la vigencia del "catedrático").

Establecido ya definitivamente en Buenos Aires, se afirma el alrededor ciudadano, circunstancia matizada por viajes y vacaciones. El paisaje "visitado", más que el paisaje vivido.

Contactos personales y amistades repercuten en una nutrida producción de "Homenajes", "Retratos" y "Salutaciones", con mucho de retórica. También, la poesía como tema. La familia - crecida- descubre otra dirección visible.

En fin, años, achaques, dolores, crisis, dan sello y signo importante a la producción final del poeta, donde, sí, debemos subrayar mayores honduras metafísicas (problema del tiempo) y muestras del tema religioso (no del todo logrado) ${ }^{11}$

Mayores lecturas (con la ayuda del "catedrático") repercuten en huellas más definidas de fuentes literarias (especialmente Antonio Machado; menos, Quevedo y García Lorca).

$\mathrm{L}_{\mathrm{a}}$ retórica busca ahora guías menos sencillas que las que descubrimos en el primer momento. $Y$, como he dicho, quizás resalte más en composiciones como las décimas (y las décimas de homenaje) sin que por eso se realce visiblemente el valor poético.

Como signos positivos, creo ver una mejor selección del adjetivo, una mayor presencia de la antítesis y del símbolo. $Y$, en conjunto, mayor afinamiento y sutileza.

En la métrica, lo característico (dentro de su abundancia) aparece en el uso más frecuente de definidas formas estróficas. Destaquemos el uso de sonetos endecasílabos (más nutridos), décimas (verdadera expansión y abundancia; cf. con el caso de Jorge Guillén), seguidillas (igualmente abundantes), romances, romancillos, cuartetos alejandrinos

10 Ver, sobre la métrica modernista, T. Navarro, Métrica española, Syracuse, 1.956, y R. Baehr (y K. Wagner y F. López Estrada), Mantual de versificación española, Madrid, 1969.

11 Ver, por ejemplo, poemas de su libro Parva, Buenos Aires, 1949. Y cf., sin intención de paralelismo, con la situación de Juan Ramón Jiménez y poemas de su época final. Sobre todo, los inçluidos en Animal de fondo. 
(con rima ABAB; cf. Antonio Machado), pareados (de verso corto o largo, como poema), pareados de alejandrinos (como poema), soleares (como poema; cf. Antonio Machado, Nuevas canciones y Cancionero apócrifo). Más raramente: la octava real y la cuaderna vía. ${ }^{12}$

Como vemos, no hay cortes rotundos, y diversos elementos que he. mos visto en el primer momento (temas, métrica, rasgos expresivos) persisten en el segundo. Pero es evidente que disponemos de un caudal lo suficientemente nítido como para establecer diferencias. Eso sí, dis. tingos que alcanzan para dos épocas ( $\mathrm{y}$-creo- no para más) y con los entrecruzamientos apuntados. Quizás también, por eso mismo, hay líneas modernistas que permanecen hasta el final de su obra.

A propósito del modernismo, y aunque parezca redundante, conviene reaccionar una vez más contra esas caracterizaciones que aún suelen leerse en algunos manuales, en los que se reduce esta corriente (o poco menos) a princesas lejanas, a abates dieciochescos y a una Grecia estilizada; a preciosismos de minoría, a un vocabulario plástico y a ciertas resonancias musicales... Recordemos, en cambio, que si hubo algunos discípulos de Darío que lo redujeron a eso, no es justo - hoy -acercar la poesía de Fernández Moreno a tan discutible identificación, ya bastante vapuleada en la época en que Fernández Moreno comenzó a escribir.

Volviendo a aspectos esenciales de la lírica de nuestro poeta, ¿cómo ejemplificamos los dos momentos señalados? Resulta notorio que, a tra. vés de los elementos que he procurado defender, un poema de cada sector no puede ostentar un nítido carácter representativo. Así, una suma, y no un poema, tendrá fuerza más convincente. Por otra parte reunir esa suma no presenta dificultades mayores.

Hecha la aclaración, podemos, con todo, tentar un cotejo que, dentro de sus límites, algo nos dice. $\mathrm{Y}$ para que el cotejo tenga sentido igualitario, me parece oportuno comparar dos sonetos. Uno, de 1918; otro, incluido en su libro póstumo de 1951.

\section{Matinal SONETO DE AMOR}

No ha de apagar su lámpara el poeta aunque el fino pincel de la mañana

12 Ver "Octavas reales a Pepito" (en Parva). Como ejemplos de cuaderna vía el poema "A Francisco de Pinedo" (1928), y el titulado, precisamente, "Cuaderna vía" (en Penumbra. Libro de Malcela, Buenos Aires, 1951). 
el desnudo cristal de la ventan:

pinte con el azul de su paleta,

sin tejer otra lírica violeta

en la ideal corona que engalana

tu divina cabeza soberana,

por buena, por hermosa y por discreta.

Vaya hacia tí mi ofrenda matutina en la luz y en el pájaro que trina. Una dulce mañana te deseo.

Asi, mientras te vayas levantando, verás mi puro corazón vibrando en un rayo de sol $y$ en un gorjeo. ${ }^{13}$

\section{EL Poeta}

La tempestad podrá en olas deshechas fingir pluma en el aire de un navio, dejando entre la sombra y el vacío erizadas las tablas más derechas.

El fuego podrá en llamas como flechas hacer cenizas del palacio frío, llevarse un pueblo desbocado río, y rebaños y bosques y cosechas.

Podrá un cuerpo caer tras la saeta, o tras la enfermedad o la locura rumiar limosna el hambre más secreta.

13 Fernández Moreno, Por el amor y por ella, Buenos Aires 1918. 
Mas siempre la canción irá a la altura.

Se yergue entre las ruinas el poeta:

No hay desventura contra su ventura. ${ }^{14}$

Repito: en un poeta de la abundancia de Fernández Moreno resulta insuficiente conceder limitador carácter "representativo" a estos dos poemas. Sin embargo, creo que, más allá de su paralelismo métrico, pueden figurar en la antología esencial del autor.

"Matinal soneto de amor" refleja un tema típico de la primera época: el amor. Por supuesto, amor optimista "juvenil", ligado a la naturaleza exterior. El sentimiento corre limpio, transparente, y la expresión, con adecuadas resonancias plásticas, luminosas. Hay ecos modernistas y notas impresionistas. Un simbolismo muy accesible atraviesa todo el soneto: luz y pájaro; sol (plenitud de vida, pureza, amor), pájaro (espítitu, comunicación). La adjetivación es simple y persistente. En fin, es el descubrimiento del mundo exterior a través del amor. Frescura y alegría son los signos notorios.

En lugar aparte, y para marcar una aproximación externa con el otro soneto, reparemos en que aquí también aparece el poeta. Si bien aquí es el poeta "activo" y como punto de referencia para algo que, en verdad, lo trasciende. Claro está: el poeta enamorado.

Como ejemplo de la segunda época he transcrito el soneto titulado "El Poeta". Este segundo soneto es, igualmente, optimista. Pero lo que vemos en él no es el tema del amor, sino el del poeta (y la poesía).

Como sabemos, éste, o éstos, son temas que realmente aparecen al avanzar la obra de Fernández Moreno, ya mire nuestro autor hacia atrás, a su propia obra, o a la obra de los demás. Ya pulse abstracciones, más que nombres concretos.

Notamos, además, una mayor presencia de precedentes literarios. Mejor dicho: entrecruzamientos de tópicos y precedentes literarios. Posiblemente Fray Luis (primer cuarteto) y Quevedo (segundo cuarteto). Agreguemos, también, la posible reminiscencia de Bécquer, a través de la reiteración en la forma verbal podrá y la oración adversativa final. ${ }^{15}$ P. 13 .

14 Fernández Moreno, Penumbra (y Libro de Marcela), Buenos Aires, 1951, de tal modo que hace irreconocible, por lo común, lo que consideramos punto de partida ajeno... 
El estímulo real nace, sin duda, en el propio poeta, en un momento de postrimerías y balances. "El Poeta" es, son otros, pero es también "él".

La estudiada disposición del soneto nos muestra el juego de sus partes internas. Los cuartetos y el primer terceto, por un lado: semejanzas y diferencia. Por otro, el segundo terceto ( $\mathrm{y}$ conclusión).

El poema culmina en el nuevo tópico que surge precisamente en el magnífico terceto final:

Mas siempre la canción irá a la altura.

Se yergue entre las ruinas el poeta:

no hay desventura contra su ventura.

Variantes de un conocido tópico: la poesía vencedora del tiempo. Los precedentes son numerosos, y muchos de ellos ilustres. Quizás, aquí, con algo de Gautier, aunque no sea fácil precisarlo. Más nos importa su concepto de la poesía, como gozoso triunfo del espíritu sobre acechanzas, embates, flaquezas, destrucción y muerte. Elementos expresionistas y símbolos.

En fin, gravedad, sensación de cansancio (más allá de su exaltación) y resonancias crepusculares. Pero brazo firme aún para proclamar excelencias del poeta. De un poeta abstracto en el cual —claro está- él se incluye púdicamente...

Concluyo. No sé si mi clasificación y fundamentaciones resultan convincentes. De todos modos han surgido como un deseo de ahondar en la rica obra lírica de Fernández Moreno. Si pretendo corregir a su hijo César, verdad es también que las incitaciones de mi clasificación algo le deben a este último. Aparte de que, es fácil mostrarlo, mis párrafos aspiran a completar $y$, en buena medida, a corregir estudios anteriores míos.

Quiero insistir, por último, en que las dos etapas que yo señalo (con las características enunciadas) están más cerca de una unidad, si no total, más defendible que la dudosa trayectoria tripartita. No he buscado a todo trance un término medio $y$, por el contrario, entiendo que - como corresponde- ha sido la propia obra del poeta la que me llevó a las conclusiones conocidas. Yo sólo he agregado explicables relaciones y fundamentos.

$Y$, aunque sea únicamente un punto de referencia general, que el 
pelfil postmodemista (perfil que he procurado precisar y que, por otra parte, no anula ramificaciones o variantes ulteriores) es el que mejor define, en su amplitud, rasgos esenciales de la lírica de Fernández Mo. reno. ${ }^{16}$

Universidad de Tacumán,

Emilio CARILLA Argentina.

16 Por supuesto, hoy no podemos contentarnos con la dimensión y contenido dados por Federico de Onís a la palabra Postmodernismo en su recordada $A n$. tología de la poesía española e bispanoamericana (1882-1932) (Madrid, 1934), donde, prácticamente, cabe en esa denominación todo lo que viene después del Modernismo.

Hoy, con una mejor perspectiva, procuramos precisarlo mejor. Lo defendemos como una ramificación parcial del Modernismo. O como movimiento que recoge sedimentaciones de éste (sobre todo, en algunos temas de un Modernismo avanzado, en novedades de la métrica, en particularidades - nunca muy efectistasde su lengua poética...).

En cambio, es evidente la reacción contra exotismos y notas históricas, contra lujos y aristocracias, contra refinamientos de vocabulario que el Modernismo más espectacular había impuesto. Pero la reacción será respetuosa, poco llamativa, como si reconociera, al mismo tiempo, lo que le debe.

En los temas, especialmente, el Postmodernismo impone un mayor reflejo de la intimidad, de lo vivido por el poeta, de lo circundante... Y, en ocasiones, llega también al tema social. Poetas como Fernández Moreno, como Gabriela Mistral, creo que ejemplifican (más allá de enriquecimientos posteriores) esta etapa literaria. Otros poetas (como Vallejo y Neruda) comenzarán como Postmodernistas, pero el desarrollo ulterior de sus obras no los mostrará en trayectoria afín a las de Fernández Mireno y Gabriela Mistral... 